\title{
Corrigendum
}

pISSN: 2234-6163 • elSSN: 2234-6171

https://doi.org/10.5999/aps.2020.02236 • Arch Plast Surg 2020;47:633

\section{Corrigendum: Two international public platforms for the exposure of Archives of Plastic Surgery to worldwide researchers and surgeons: PubMed Central and Crossref}

\section{Sun Huh}

Department of Parasitology and Institute of Medical Education, Hallym University College of Medicine, Chuncheon, Korea

Arch Plast Surg 2020;47:377-381.

https://doi.org/10.5999/aps.2020.01697

In the version of this article initially published, at the top of the left column on page 377, the year was incorrectly spelled.

The correction is given below (marked in bold):

Page 377, left column

From:

After changing the language of its articles from Korean or English to English only in 2012 [1], Archives of Plastic Surgery (APS) became an international journal, as evidenced by various metrics [2] and its inclusion in the Web of Science Core Collection in (2012) and Scopus in 2013.

To:

After changing the language of its articles from Korean or English to English only in 2012 [1], Archives of Plastic Surgery (APS) became an international journal, as evidenced by various metrics [2] and its inclusion in the Web of Science Core Collection in (2016) and Scopus in 2013. 